Biology | Mike Eichholz

\title{
How natural disturbances sustain diversity
}

While natural disturbances like fires and floods can pose a risk to human life, in some places these events can help to support for exe cos for example, allow species like insect population which in turn feeds many different birds. Dr Mike Eichholz of Southern Illinois University Carbondale studies the influence of habitat management - including allowing or preventing natural disturbances - on bird populations. Understanding informs forest managens practices that support
biodiversity.

Woodpecker eating insects:
Adiverse community A diverse commun
of anthropods

\section{of anthropods
also supports
greater variety}

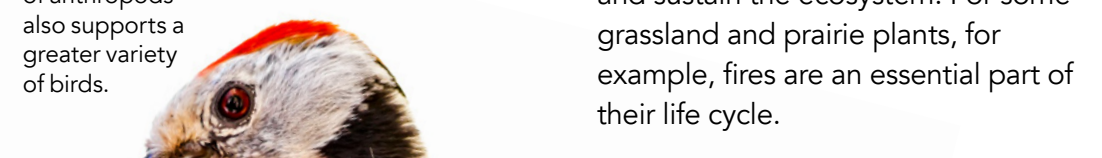
their life cycle.

Around the world, suppression of natural disturbances is causing unprecedented change to ecosystems. This has plant and animal life, from the small insects to the tallest trees. The potentia result is a widespread loss of biological diversity. This does not only happen in by human actions; the effects also spread to other areas as the unintended consequences proliferate.

To protect and support a diverse ecosystem, a better understanding
of how human actions - including burnt an enormous 186,000 square
kilometres of land. The season, often referred to as "Black Summer" by almost 6,000 buildings and 34 deaths. Shortly earlier, the 2019 California wildfire Natural disturbances like wildfires are normally seen as a negative event, as those of Australia and California. can pose a threat to human life and property. Governments put huge effort (t) is that, for some natural communities, disturbances actually help to create and sustain the ecosystem. For som

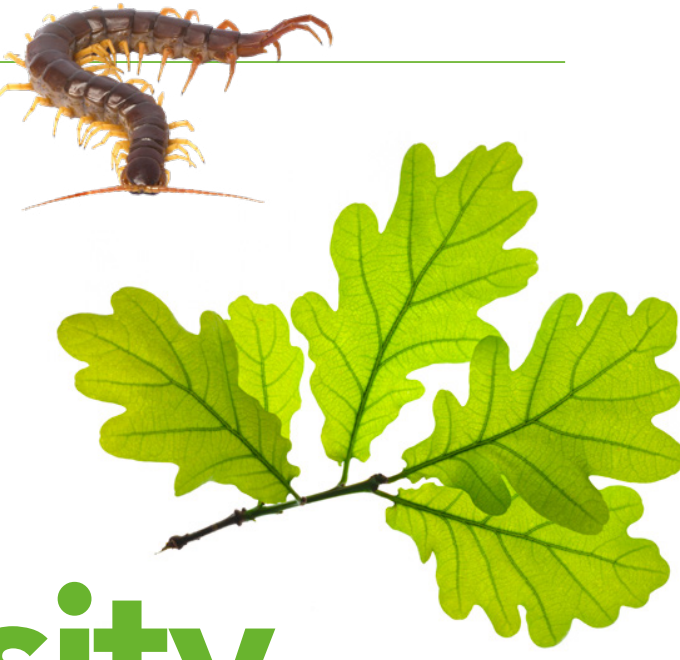
season involved the burning of more tha preventing natural disturbances like fire od - affect the natural world is urgently needed.

\section{CHANGING FORESTS}

Perhaps some of the most important

includes insects, spiders and centipedes, are the most abundant creatures in the animal kingdom. One of their many roles in the ecosystem is as food for other animals, including numerous species of birds; woodpeckers, for example, famously eat bark-dwelling insects.

Dr Mike Eichholz, an avian ecologist at Southern Illinois University Carbondale, is interested in the relationships between insect-eating birds and their prey. Broadly speaking, a more diverse support a greater variety of able to Which arthropods are found in a given area grow in that environment In ecosystem which rely on natural disturbances, the plant community can undergo dramatic changes when those disturbances are suppressed by human activity. When the plants change, so do the arthropods they support.

Dr Eichholz and his colleagues hope to discover what happens to the arthropod and bird populations when recent work, Dr Eichholz and his team compared different types of woodland USA the last few in this region of the gradual change in forest composition as least visible. Anthropystem are the is inextricably linked to the plants that natural disturbances are restricted. In

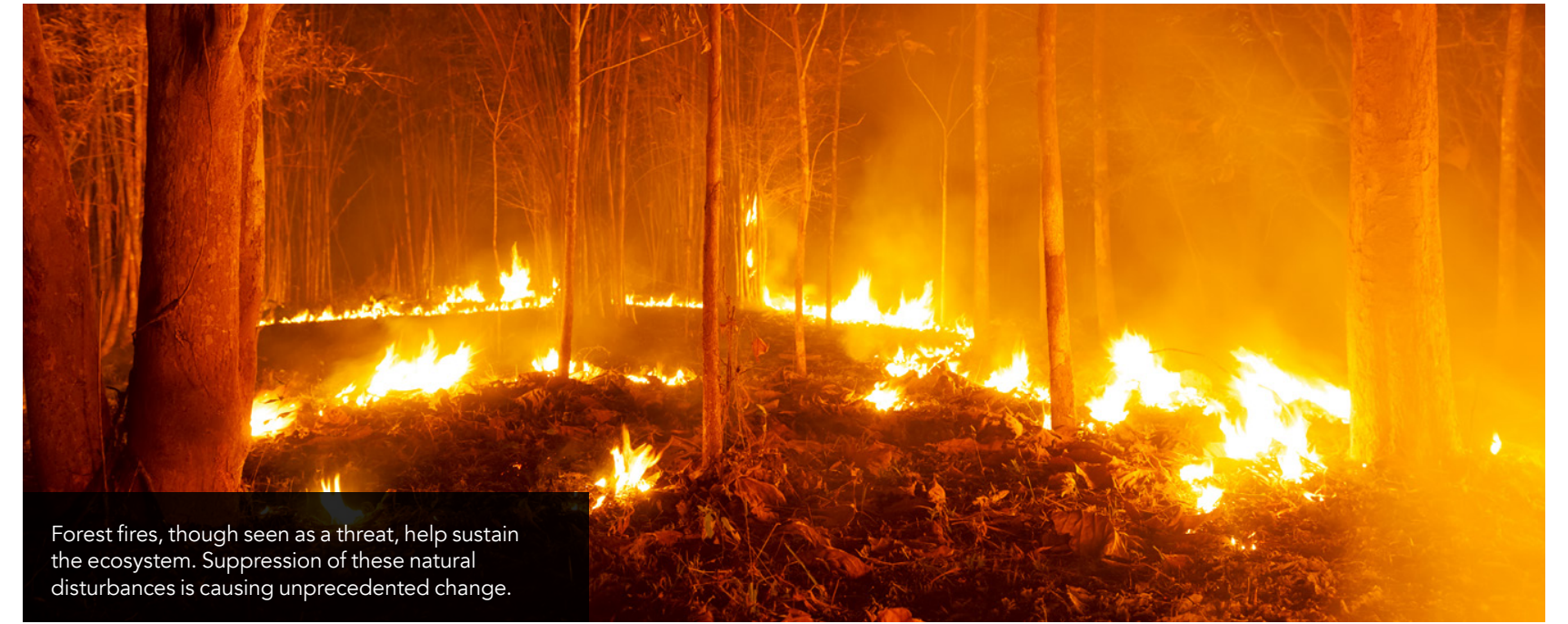

In ecosystems which rely on natural disturbances, the plant community can undergo dramatic changes when disturbances are suppressed.

a result of suppressed
particular forest fires.

In a process called mesophication shade-tolerant species in this area such as maple and beech, have been increasingly able to out-compete and replace trees which prefer drier conditions and a more open canopy, like oak and hickory. Maple and beech are known as end-succession species. Succession is the change in species in a comm te ty over time, leading to, for example, a mature forest. Oak and hickecies, and are commidsuccession species, and are coms miny foundin by disturbances such as wildfires.

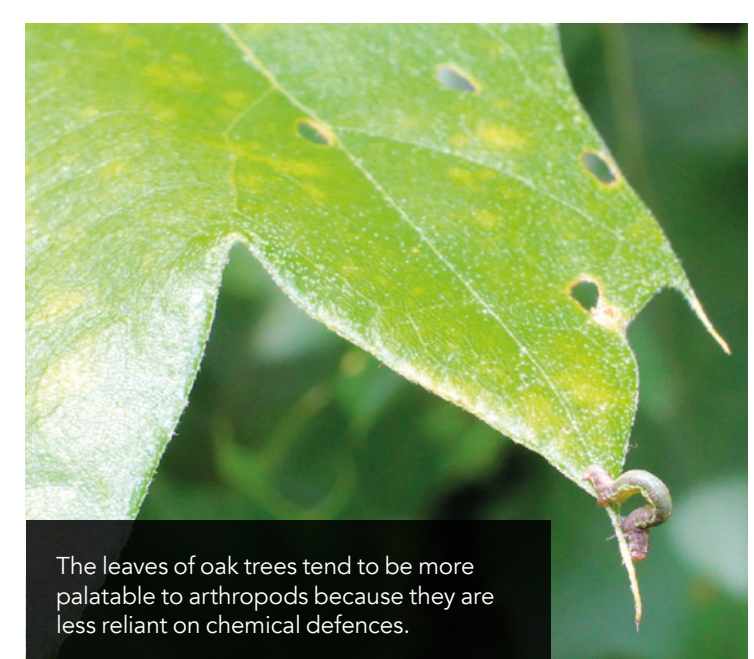

Dr Eichholz and his team carried out detailed studies of the types and numbers of arthropods present in woodland dominated by oak and hickory trees, and beech. The researchers suspected that more arthropods, in terms of both numbers and diversity, would be found in oakhickory areas than in maple/beech woodland. This is because the leaves of oak and hickory tend to be more palatable to arthropods, as the trees are predation companical te ofences to avoid Also, the bark of oak and hickory trees Also, the bark of oak and hickory trees ainst overheating: these furrows also

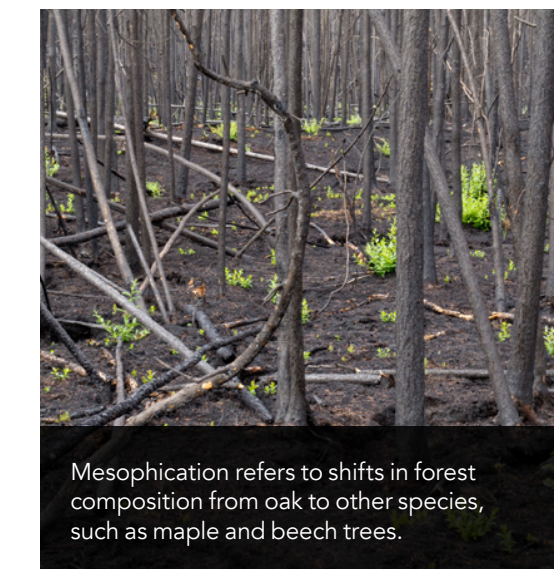

arthropod. Birds which feed on insects

IN SEARCH OF ARTHROPODS

\section{Trescholz and} his colleagues examined a number different sites within the Shawnee the summers of 2014 and 2015. In the

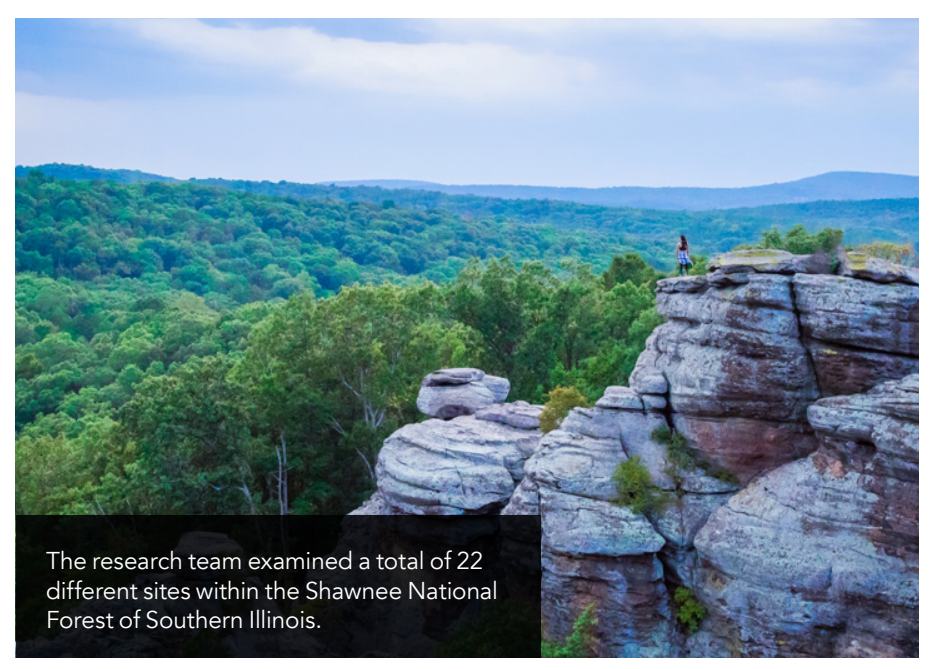


2014 study, a total of 22 sites were selected. Some wer dominated by oak maple and beech. Our the course one month, the researchers collected arthropods at each of the 22 sites using a method called branch-clipping (clipping tree branches encased in plastic collection bags with a long-handled clipper). The results supported the researchers' predictions: more arthropods were found in oak and hickory trees compared to maple and beech.

In the second study, carried out in July 2015, six sites were selected. Three sites were dominated by oak and hickory, white the other three held mostly maple and beech. This time, the team set insect traps around the trunk of a total of 54 individu trees. Afternine days, the arthropods in

The researchers found that, at the time of the study (July) hickory trees do support more arthropods than maple and beech. Over $70 \%$ of the arthropods collected from hickory trees belonged to the orders Hymenoptera (which includes ants, bees and wasps) or Orthoptera (grasshoppers, locusts and crickets.) These arthropods are known to make up an important part of the diet of birds that feed on bark-dwelling insects. Interestingly - and contrary to the researcher's predictions - there was little difference in the abundance of arthropods on oak, maple and beech trees. This suggests that something other than bark texture could be responsible for the

Both studies found both the highest number, and greatest diversity of arthropods living on hickory trees. This

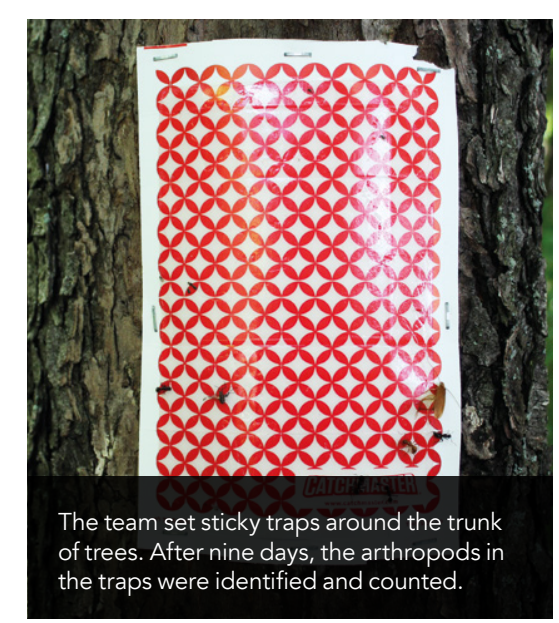

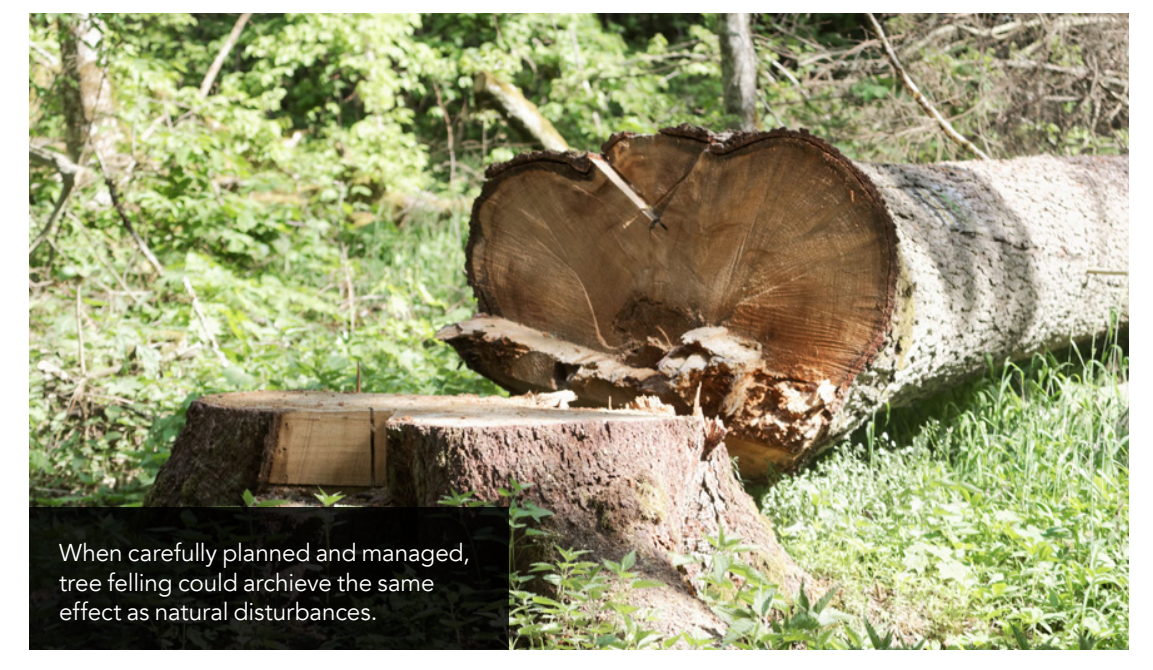

Forest management should aim to slow the mesophication process and allow species like oak and hickory to continue to thrive.

suggests that the foliage of these trees If the shift towards end-succession is most palatable to insects - even the species like beech and maple continues surrounding leaf litter could harbour more species.

\section{MANAGING DISTURBANCE}

COULD SUPPORT DIVERSITY

The research of Dr Eichholz and his

colleagues supports the idea that some

species of fire-dependent trees support

more arthropods. These arthropods, which

are found in the bark and amongst the foliage of trees like oak and hickory, are an birss and mat of the diet of insect-eating birds and mammals. Sadly, insectivorous
birds are already in decline in many parts birds are aleady in decliy in many parts of in their habitat. If the shift towards trees that support fewer arthropods continues, they could also be in danger in the forests studied in this research.

Dr Eichholz believes that forest management should aim to slow the mesophication process and allow species like oak and hickory to continue to thrive. These trees, with their richer population of arthropods, are better able to support a healthy community of birds. Although the data gathered by Dr Eichholz and his colleagues suggests that hickory trees support a greater abundance of antropods than oaks, the two trees favour similar conditions. Therefore, forest management that aims to conserve species like beech and maple continues unchecked, Dr Eichholz believes that like woodpeckers and nuthatches play vital roles in the ecosystem, including maintaining tree health by controlling insect populations. Losing these species disastrous consequences.

While the ideal way to control mesophication, from an ecologica perspective, might be to allow
disturbances to happen - for ex disturbances to happen - for example, would be difficult to achieve in a safe and socially acceptable way. Dr Eichho recommends that alternative solutions should be explored in at-risk areas. For example, tree felling, when carefully planned and managed, could achieve the same effect as natural disturbances.

The relationships within an ecosystem are complex, delicate and only partially understood. While the work of Dr Eichholz and his colleagues tocuses on birds and arthropods it also demonstrates the value of of all ecosystem relationships. Understanding how even small parts of the natural world function will help to on bark-dwelling arthropods. Species further research into the intricacies

\section{Behind the Research}

\section{Dr Mike Eichholz}

E: eichholz@siu.edu T: +1 6182012376 T: +1 6184536951 W: http://eichholz.wix.com/avian-ecology-lab

\section{Research Objectives}

Dr Eichholz and his team study how the lack of largescale disturbances such as wildfires impacts the species trophic organisms such as birds.

\section{Detail}

\section{Dr Mike Eichholz}

CWRL, Room 251, Life Science II

SIUC

Carbondale, IL 6290

USA

Bio

Drich is an avian ecologist in the Cooperative Wildlife Research Laboratory, Professor of Zoology and Director of the Professional Science Master's Program Din Wid fe Administration and Management at Southen linois University Carbondale. Dr Eichholz's primary on bird population dynamics.

Funding

Fited Forest Service, United States Fish and Wildifife Service, Delta Waterfowl Foundation, Illinois and Fish Department Kulm Wethand Makota Ga Tewaukon National Wild life Refuge, Sand Lake National Wildlife Refuge, The Nature Conservancy-Ordway Praite, National Science Foundation

\section{Collaborators}

Ryan Haffele

- John Dassow

- Ashlee Minor

- Alex Glass

- Caleb Crawford

- Elise Zarri

- Josh Stafford

$\mathbb{S I U}$ Southern Illinois

\section{References}

Sierzega, K. and Eichholz, M. (2019). Linking conservation implications of modified disturbance regimes, plant communities, plant associations, and arthropod communities. Oecologia, 189, 267-277.

Zarri, E., Eichholz, M. and Sierzega, K. (2020). Potential influences of forest mesophication on corticolous arthropods Forest Ecology and Manares in eastern decid Hes://doiog/10.1016/j foreco 2020.117933

\section{Personal Response}

How could this work influence research in other types

II My colleagues and I have found similar results in studies of grassland systems. Grassland birds are the group of birds showing the greatest rate of decline in are needed to maintain grassland plant species diversity. od, small mammal, bird, and nest predator diversity and abundance. These factors interact to influence grassland bird nest site selection and
productivity.

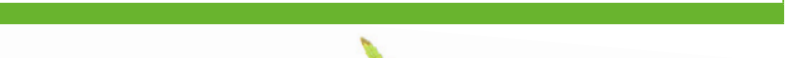

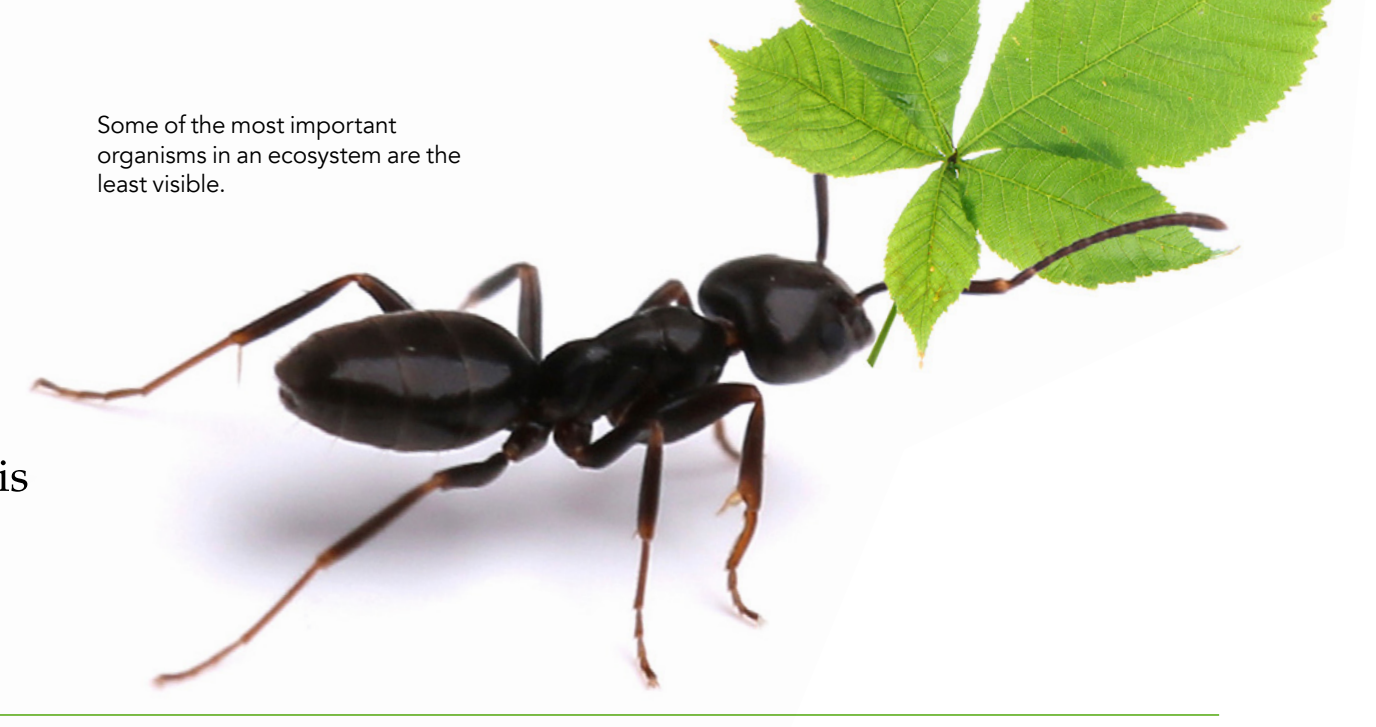

